\title{
Effects of Tim-3 silencing on the viability of fibroblast-like synoviocytes and lipopolysaccharide-induced inflammatory reactions
}

\author{
RUI WU, LI LONG, QIQI CHEN, XIAODAN WU, JING ZHU, BIN ZHOU and JIA CHENG \\ Department of Rheumatology and Immunology, Sichuan Academy of Medical Sciences, \\ Sichuan Provincial People's Hospital, Chengdu, Sichuan 610072, P.R. China
}

Received August 16, 2016; Accepted May 16, 2017

DOI: $10.3892 /$ etm.2017.4819

\begin{abstract}
The objective of the present study was to investigate the effects of Tim-3 silencing on cell viability and lipopolysaccharide (LPS)-induced inflammatory reactions in fibroblast-like synoviocytes (FLS). T-cell immunoglobulin mucin domain molecule (Tim)-3 expression in FLS obtained from patients with rheumatoid arthritis (RA) and normal controls were detected by western blot analysis and reverse transcription-polymerase chain reaction (RT-PCR). Small interfering (si)RNA was transfected using Lipofectamine ${ }^{\circledR} 2000$ to decrease Tim-3 expression. Following transfection, FLS were stimulated by LPS. An MTT assay, RT-PCR and western blot analysis were performed to measure cell viability, Toll-like receptor 4 (TLR4) signaling pathway-related protein expression and inflammatory cytokine release, respectively. The results of the present study indicated that Tim-3 expression was increased in FLS from patients with RA compared with FLS from healthy controls. Transfection of Tim-3 siRNA significantly decreased Tim-3 expression in FLS from patients with RA. Notably, Tim-3 silencing decreased FLS cell viability. Following stimulation with LPS, cell viability and the expression of TLR4, myeloid differentiation protein gene 88 (MyD88) and nuclear factor- $\kappa \mathrm{B}(\mathrm{NF}-\kappa \mathrm{B}) \mathrm{p} 65$ were enhanced in FLS. By contrast, Tim-3 silencing attenuated LPS-induced cell proliferation and the expression of TLR4, MyD88 and $\mathrm{NF}-\kappa \mathrm{B}$ p65. In addition, LPS significantly increased levels of cytokines in the supernatant, including tumor necrosis factor- $\alpha$, interferon- $\gamma$ and interleukin- $6(\mathrm{P}<0.01)$. By contrast, Tim-3 silencing significantly decreased LPS-induced cytokine release $(\mathrm{P}<0.01)$. However, Tim-3 silencing did not affect
\end{abstract}

Correspondence to: Dr Jia Cheng, Department of Rheumatology and Immunology, Sichuan Academy of Medical Sciences, Sichuan Provincial People's Hospital, 32 West of First Ring Road, Chengdu, Sichuan 610072, P.R. China

E-mail: jiacheng_12@sohu.com

Key words: T-cell immunoglobulin mucin domain molecule-3, rheumatoid arthritis, fibroblast-like synoviocytes, Toll-like receptor 4
TLR4, MyD88 and NF- $\mathrm{B}$ p65 expression and the release of cytokines in cells that did not undergo treatment with LPS. Therefore, the results of the present study indicate that Tim-3 silencing decreases the viability of FLS in RA and attenuates the LPS-induced inflammatory reaction.

\section{Introduction}

Rheumatoid arthritis (RA) is a type of autoimmune disease, primarily characterized by the proliferative and destructive inflammation of the synovium $(1,2)$. Recurrent synovitis contributes to the loss of joint structure and function. RA not only has a high incidence $(0.5-1 \%$ in adults from developed countries) but also has a high mortality rate ( 30,000 globally) (3). T helper (Th) cell-mediated immune responses and inflammatory cytokines perform critical roles in the development of RA. Specifically, Th 1 cells are highly activated in the synovial fluid, which is able to secrete a large number of inflammatory cytokines including tumor necrosis factor- $\alpha$ (TNF- $\alpha)$, interferon- $\gamma($ IFN- $\gamma)$ and interleukin (IL)- 6 that damage the articular synovium and bone (4-6). Fibroblast-like synoviocytes (FLS) are one of the most important types of synovial cells. Following stimulation by pathological factors, FLS release various cytokines to facilitate joint destruction (7).

Toll like receptor (TLR) is a type of inherent immune receptor and may be activated by its ligands, such as lipopolysaccharide (LPS) (8). The downstream signaling pathway consists of recruiting bone marrow myeloid differentiation protein gene 88 (MyD88) and activating the tumor necrosis factor- $\kappa \mathrm{B}(\mathrm{NF}-\kappa \mathrm{B})$ p65 signaling pathway, which regulates the expression of inflammatory cytokines and promotes the immune response $(9,10)$. Previous studies have implicated that the TLR4 signaling pathway is activated in RA and that activation of the TLR4 signaling pathway is closely associated with the onset and development of RA (11-13).

The T-cell immunoglobulin mucin domain molecule (Tim) gene family was initially identified in 2001 (14). This gene family is located on human chromosome 5 and 3 different subtypes have been identified so far: Tim-1, Tim-2 and Tim-3 (15). Tim-3 is considered to be a specific surface marker of Th1 cells and is able to regulate the 
immune response of Th1 cells to participate in systemic lupus erythematosus, aplastic anemia and other autoimmune diseases $(16,17)$. Furthermore, Tim-3 is highly expressed in cluster of differentiation (CD) $4^{+} \mathrm{T}$ cells, as well as the synovial tissue of patients with RA (17-19). Tim-3 is closely associated with the TLR4 signaling pathway and participates in a variety of immune diseases by regulating this signaling pathway $(20,21)$. The present study hypothesized that Tim-3 may be involved in the onset and development of RA by mediating the TLR4 signaling pathway. To verify this hypothesis, FLS was selected as the cell model to demonstrate the effect of Tim-3 silencing on FLS cell viability and LPS-induced inflammatory reactions.

\section{Materials and methods}

Cell culture. Synovial tissue was obtained from 20 patients with rheumatoid disease who had surgery to replace a knee joint at the Sichuan Provincial People's Hospital, (Sichuan, China) between June 2015 and June 2016. Of the 20 patients, 5 were male and 15 were females, with a mean age of 53 years. All patients with RA were diagnosed according to the standard for the American College of Rheumatology Classification Criteria (22). Normal synovial tissue was obtained from 10 healthy controls ( 5 male and 5 female patients with a mean age of 38 years) that had undergone amputation between June 2015 and June 2016 in the Orthopedics Department due to accidents but did not have rheumatoid disease. Informed consent was obtained from each patient and the experimental protocol was approved by the Ethics Committee of Sichuan Provincial People's Hospital.

Synovial tissues were washed with phosphate buffered saline (PBS) under sterile conditions and adipose tissue was removed. Synovial tissues were cut and digested using trypsin and collagenase for $30 \mathrm{~min}$ and $3 \mathrm{~h}$, respectively. Cell suspensions were obtained by centrifugation $(987 \times \mathrm{g}$ for $4 \mathrm{~min}$ at room temperature) and cultured in Dulbecco's modified Eagle's medium (Gibco; Thermo Fisher Scientific, Inc., Waltham, MA, USA) supplied with $10 \%$ fetal bovine serum (Hyclone; GE Healthcare Life Sciences, Logan, UT, USA), 100 U/ml penicillin and $100 \mathrm{U} / \mathrm{ml}$ streptomycin in an incubator at $37^{\circ} \mathrm{C}$ containing $5 \% \mathrm{CO}_{2}$. The second or third generation of FLS was used in subsequent experiments.

Reverse transcription polymerase chain reaction (RT-PCR). RNA was extracted from FLS using a TRIzol assay kit (Baosheng Science \& Technology Innovation Co, Ltd., Shanghai, China). The purity of RNA was confirmed by assessing the optical density (OD)280/OD260 by spectrophotometer (Shanghai Precision Instrument Co., Ltd., Shanghai, China). RNA was reversed-transcribed into cDNA using a one-step reverse transcription kit according to the manufacturer's protocol (catalogue no. RR055A; Takara Biomedical Technology Co., Ltd., Beijing, China) and amplified in a $25 \mu \mathrm{l}$ PCR reaction system (HiFiScript cDNA; catalogue no. YJ2569; CW Biotech, Beijing, China) for PCR (UItraSYBR Mixture; CW Biotech) following treatment with DNA polymerase (catalogue no. EP0041; Thermo Fisher Scientific, Inc.) as follows: Denaturation at $94^{\circ} \mathrm{C}$ for $45 \mathrm{sec}$, annealing at $59^{\circ} \mathrm{C}$ for $45 \mathrm{sec}$ and extension at $72^{\circ} \mathrm{C}$ for $60 \mathrm{sec}$ for 35 cycles as previously described (23). The primer sequences used for Tim-3, TLR4, MyD88, NF-кB p65 and GAPDH are presented in Table I. PCR products were detected by $2 \%$ agarose gel electrophoresis with ethidium bromide staining and the density of the band was analyzed by ImageJ Software v1.48u (National Institutes of Health, Bethesda, MA, USA).

Transfection of FLS with siRNA. FLS $\left(3 \times 10^{5} / \mathrm{ml}\right)$ were cultured in 96 -well plates at $37^{\circ} \mathrm{C}$. When the cells reached $50 \%$ confluence, siRNA Tim-3 and control siRNA (Shanghai GenePharma, Co., Ltd., Shanghai, China) were transfected using Lipofectamine ${ }^{\circledR} 2000$ (Shanghai Jima Industrial Co., Ltd., Shanghai, China). $1 \mu \mathrm{g} / \mathrm{ml}$ LPS (Aladdin Shanghai Biochemical Technology, Co., Ltd., Shanghai, China) was added to the cells, $6 \mathrm{~h}$ after transfection.

MTT assay. Cell viability was detected by MTT assay (Gibco; Thermo Fisher Scientific, Inc., Waltham, MA, USA) 48 h following transfection, as previously described (17). Purple formazan crystals were dissolved in dimethyl sulfoxide and absorbance was measured using a microplate reader (Thermo Fisher Scientific, Inc.) at a wavelength of $560 \mathrm{~nm}$.

Western blot analysis. Following transfection, FLS were collected and the protein was extracted for western blot analysis $48 \mathrm{~h}$ later, as previously described (23). The antibodies, including anti-Tim-3 (catalogue no. ab185703), anti-TLR4 (catalogue no. ab13556), anti-MyD88 (catalogue no. ab2068), anti-NF-кB p65 (catalogue no. ab207297; all 1:1,000; Abcam, Cambridge, UK) and anti-GAPDH (1:1,000; catalogue no. AG019, Beyotime Institute of Biotechnology) were incubated overnight at $4{ }^{\circ} \mathrm{C}$ at a dilution of 1:100. After washing with $0.1 \%$ PBST $(0.1 \%$ Tween-20), membranes were probed with anti-mouse immunoglobulin (Ig) $\mathrm{G}$ or anti-rabbit IgG horseradish peroxidase-conjugated secondary antibodies $(1: 100$; catalogue nos. ab131368 and ab191866, respectively; Abcam) at room temperature for $2 \mathrm{~h}$. The ECL reagent kit (catalogue no. RPN2133; GE Healthcare Life Sciences, Chalfont, UK) was applied to assist the staining. The blots were scanned using a ChemiDocTM XRS (Bio-Rad Laboratories, Inc., Hercules, CA, USA) and grey density was analyzed using Quantity One analysis software v1.4.6 (Bio-Rad Laboratories, Inc.).

ELISA. The supernatant was collected to complete ELISA $48 \mathrm{~h}$ after transfection. TNF- $\alpha$ (catalogue no. ab181421), IFN- $\gamma$ (catalogue no. ab46025) and IL-6 (catalogue no. ab46027; All Abcam) levels were determined following the instructions of the specific assay kits.

Statistical analysis. All experiments were repeated at least three times and data are presented as mean \pm standard deviation. Statistical analysis was performed using version 17.0 of SPSS (SPSS, Inc., Chicago, IL, USA). Student's t test was used to analyze the differences and $\mathrm{P}<0.05$ was considered to represent a significant difference.

\section{Results}

Tim-3 expression is increased in RA FLS. The expression of Tim-3 mRNA and protein was assessed. The expression 
Table I. Primers for Tim-3, TLR4, MyD88, NF-кB p65 and GAPDH.

\begin{tabular}{|c|c|c|c|}
\hline Gene & Direction & Primer sequence $\left(5^{\prime}-3^{\prime}\right)$ & Length, bp \\
\hline Tim-3 & $\begin{array}{l}\text { Forward } \\
\text { Reverse }\end{array}$ & $\begin{array}{l}\text { CCAGAGACTGTTAATCAT } \\
\text { ATGATTAACAGTCTCTGG }\end{array}$ & 749 \\
\hline TLR4 & $\begin{array}{l}\text { Forward } \\
\text { Reverse }\end{array}$ & $\begin{array}{l}\text { GAGCCGTTGGTGTATCTTTGA } \\
\text { CTCCCATTCCAGGTAGGTGTT }\end{array}$ & 166 \\
\hline MyD88 & $\begin{array}{l}\text { Forward } \\
\text { Reverse }\end{array}$ & $\begin{array}{l}\text { CTTTATCTGCATACTGCCCCAAC } \\
\text { CAAACTTGGTCTGGAAGTCACA }\end{array}$ & 230 \\
\hline $\mathrm{NF}-\kappa \mathrm{B}$ p65 & $\begin{array}{l}\text { Forward } \\
\text { Reverse }\end{array}$ & $\begin{array}{l}\text { TGCGAATGGAGCGACACG } \\
\text { CACCCTGTGCTGCTCACCGAGGCC }\end{array}$ & 122 \\
\hline GAPDH & $\begin{array}{l}\text { Forward } \\
\text { Reverse }\end{array}$ & $\begin{array}{l}\text { AGCCACATCGCTCAGACA } \\
\text { TGGACTCCACGACGTACT }\end{array}$ & 314 \\
\hline
\end{tabular}

Tim-3, T-cell immunoglobulin mucin domain molecule-3; TLR4, Toll-like receptor 4; MyD88, myeloid differentiation protein gene 88; NF- $к B$, nuclear factor- $\mathrm{\kappa B}$; bp, base pairs.
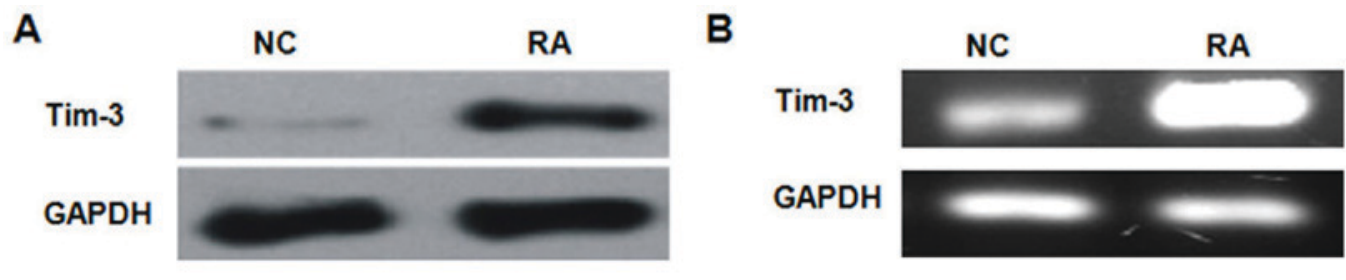

Figure 1. Tim-3 expression in fibroblast-like synoviocytes from patients with RA and NCs. (A) Protein and (B) mRNA expression. Tim-3, T-cell immunoglobulin mucin domain molecule-3; RA, rheumatoid arthritis; NC, normal control.

of Tim-3 protein was markedly upregulated in RA FLS (Fig. 1A). Furthermore, levels of Tim-3 mRNA were markedly increased in RA FLS compared with the control (Fig. 1B). These results suggest that Tim-3 may be a target for RA therapy.

Tim-3 silencing attenuates LPS-induced Tim-3 expression. The siRNA for Tim-3 was designed to decrease Tim-3 expression. As presented in Fig. 2, siRNA significantly attenuated the expression of Tim-3 protein and mRNA $(\mathrm{P}<0.01$; Fig. 2B and D).

The present study also analyzed the effects of Tim-3 silencing on LPS-induced Tim-3 expression. As presented in Fig. 3, LPS treatment significantly increased Tim-3 protein and mRNA expression ( $\mathrm{P}<0.01$; Fig. 3B and D). Tim-3 silencing not only significantly decreased Tim -3 expression in RA FLS $(\mathrm{P}<0.01)$, but also significantly decreased LPS-induced Tim-3 expression ( $\mathrm{P}<0.01$; Fig. 3B and D). It was confirmed that Tim-3 silencing significantly decreased the LPS-induced increase in Tim-3 mRNA and protein expression ( $\mathrm{P}<0.01$; Fig. $3 \mathrm{~B}$ and $\mathrm{D})$.

Tim-3 silence decreases the viability of FLS from patients with $R A$. Compared with the control, Tim-3 silencing significantly decreased the viability of FLS ( $\mathrm{P}<0.01$; Fig. 4). However, LPS treatment also significantly increased the cell viability of FLS transfected with control siRNA and Tim-3 siRNA $(\mathrm{P}<0.01)$. Furthermore, compared with the control siRNA, Tim-3 silencing significantly attenuated the increase in cell viability induced by treatment with LPS ( $\mathrm{P}<0.01$; Fig. 4).
Tim-3 silencing decreases TLR4, MyD88 and NF- $\mathrm{B}$ p 65 expression. The effect of Tim-3 silencing on inflammation-associated gene expression was evaluated. LPS treatment significantly increased the expression of TLR4, MyD88 and NF- - B p 65 mRNA and protein $(\mathrm{P}<0.01$; Fig. 5). Furthermore, Tim-3 silencing attenuated the LPS-induced increase of the expression of these genes at the mRNA and protein level $(\mathrm{P}<0.01$; Fig. 5). By contrast, there were no significant differences between the expression of TLR4, MyD88 and NF- $\kappa \mathrm{B}$ p65 mRNA and protein in FLS transfected with Tim-3 siRNA compared with those transfected with control siRNA that did not undergo LPS treatment (Fig. 5C-H).

Tim-3 silencing decreases TNF- $\alpha$ INF- $\gamma$ and IL-6 levels. The current study measured TNF- $\alpha$, IFN- $\gamma$ and IL- 6 levels in FLS and it was determined that LPS treatment significantly increased levels of TNF- $\alpha$, IFN- $\gamma$ and IL- 6 in FLS $(\mathrm{P}<0.01$; Fig. 6). Tim-3 silencing did not significantly affect cytokine release in FLS that did not undergo treatment with LPS, however it did significantly decrease the release of cytokines in FLS treated with LPS $(\mathrm{P}<0.01$; Fig. 6).

\section{Discussion}

RA is a type of autoimmune disease characterized by synovial inflammation, which is characterized by the excessive proliferation and invasion of synovial cells, as well as production of invasive pannus $(1,2) \cdot \mathrm{CD}^{4+} \mathrm{T}$ cells in the synovial tissue of patients with RA are activated and 

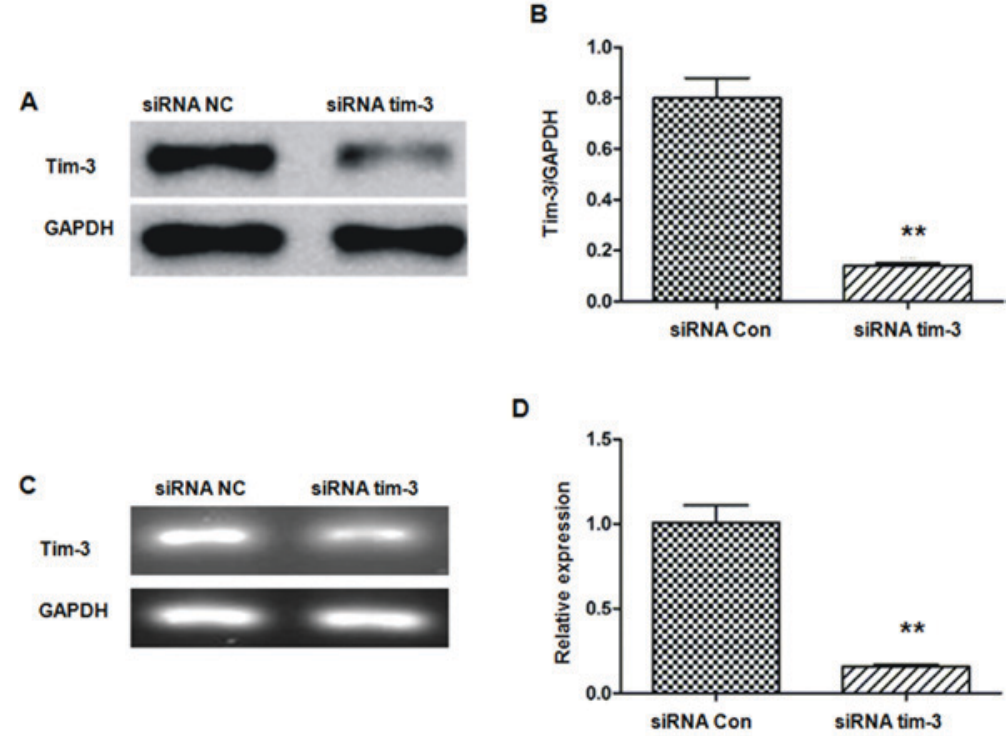

Figure 2. Tim-3 silencing decreases Tim-3 expression in fibroblast-like synoviocytes. (A) Representative blots for Tim-3 protein and GAPDH, (B) quantified and (C) representative bands of Tim-3 mRNA and GAPDH, (D) quantified. ${ }^{* *} \mathrm{P}<0.01$ vs. siRNA NC. Data are presented as the mean \pm standard deviation. Tim-3, T-cell immunoglobulin mucin domain molecule-3; NC, normal control; Con, control; siRNA, small interfering RNA.

A

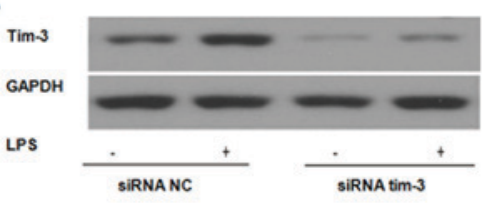

c

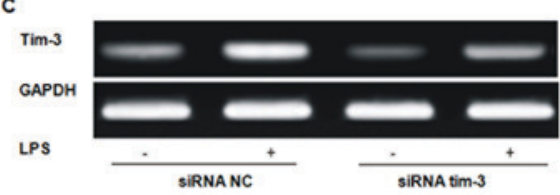

B
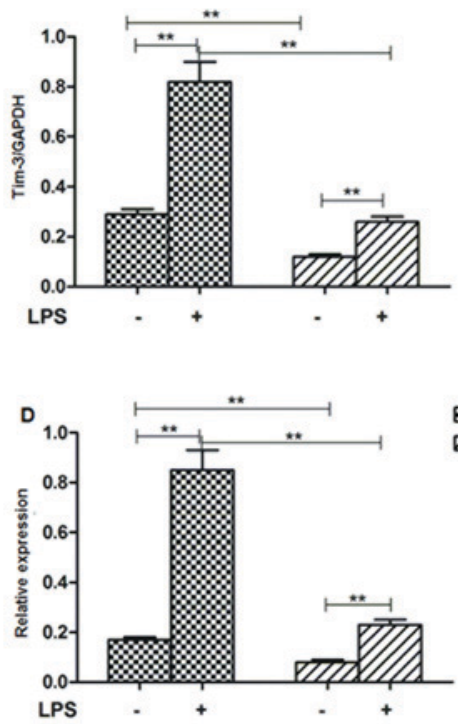

Figure 3. Tim-3 silencing decreased Tim-3 expression in LPS-treated and untreated fibroblast-like synoviocytes. (A) Representative blots for Tim-3 protein expression (B) quantified and (C) representative bands of Tim-3 mRNA expression (D) quantified. ${ }^{* *} \mathrm{P}<0.01$. Data are presented as the mean \pm standard deviation. Tim-3, T-cell immunoglobulin mucin domain molecule-3; LPS, lipopolysaccharide; NC, normal control; siRNA, small interfering RNA.

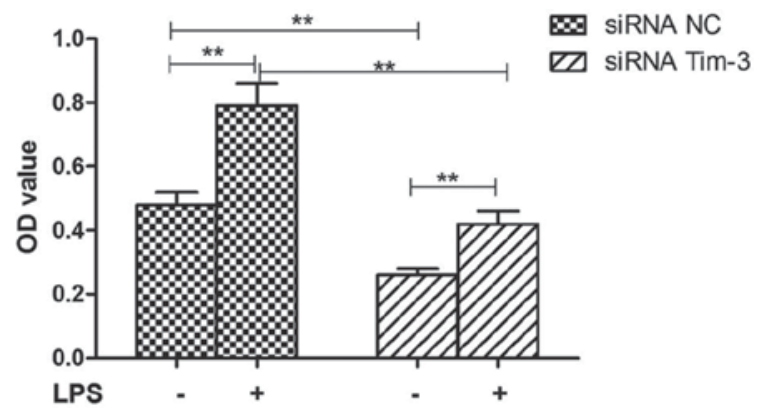

Figure 4. OD of each group indicating the viability of fibroblast-like synoviocytes with and without LPS treatment. ${ }^{* *} \mathrm{P}<0.01$. Data are presented as the mean \pm standard deviation. OD, optical density; NC, normal control; Tim-3 T-cell immunoglobulin mucin domain molecule-3; LPS, lipopolysaccharide; siRNA, small interfering RNA. a large number of inflammatory factors are secreted to stimulate the synovial proliferation and invasion of blood vessels, which ultimately leads to the destruction of bone and cartilage (4-6). FLS is one of the effective cells involved in the development of RA and is also the primary component of synovial cells, which exhibit 'tumor-like' invasion activity (24). In a hypoxic environment, FLS is stimulated by Th1 inflammatory cells to activate a variety of signaling pathways involved in the onset and development of RA (19). Therefore, FLS were selected as the targeted cells in the present study. The current study compared Tim-3 expression in FLS from patients with RA to that of normal controls. FLS cells were stimulated with LPS and the function of Tim-3 was subsequently investigated. 

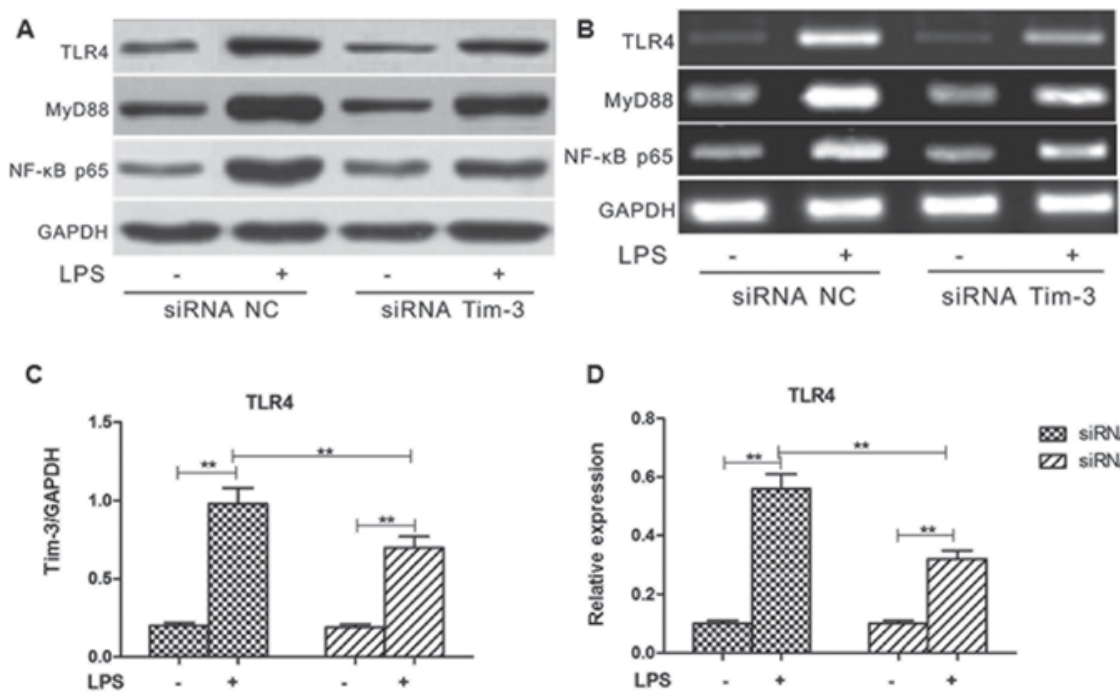

\section{D}

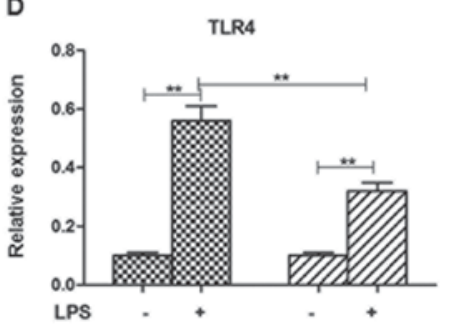

$\otimes$ SiRNANC

E

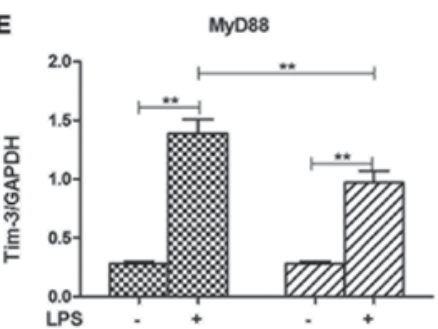

$\mathbf{F}$

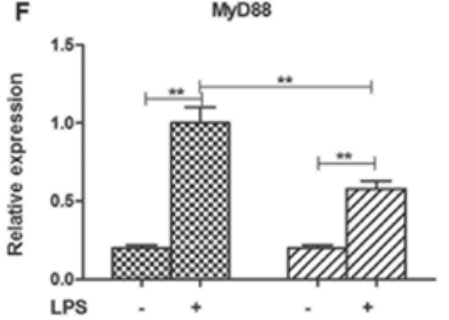

$\otimes$ SIRNANC

ED SiRNA Tim-3i
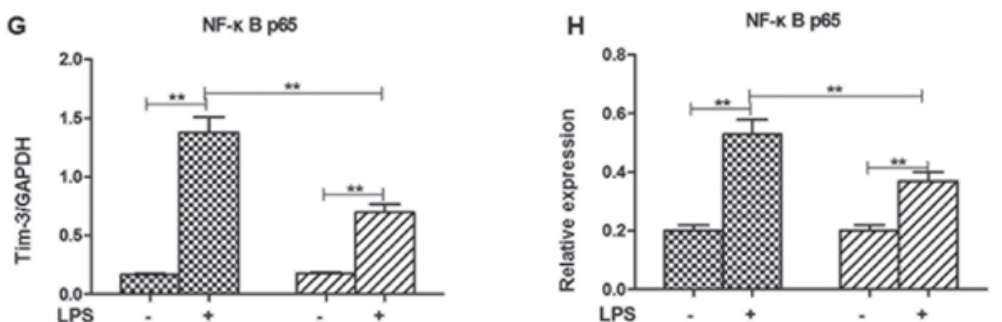

$\infty$ SIRNANC

ED siRNA Tim-3:

Figure 5. Tim-3 silencing attenuates the LPS-induced increases in the expression of TLR4, MyD88 and NF-kB p65. (A) Representative blots for TLR4, MyD88, NF-kB p65 (A) protein and (B) mRNA expression. Quantified data of TLR4 expression at the (C) protein and (D) mRNA level. Quantified data of MyD88 expression at the (E) protein and (F) mRNA level. Quantified data of NF- $\kappa B$ p65 expression at the $(\mathrm{G})$ protein and $(\mathrm{H}) \mathrm{mRNA}$ level. ${ }^{* *} \mathrm{P}<0.01$. Data are presented as the mean \pm standard deviation. Tim-3, T-cell immunoglobulin mucin domain molecule-3; LPS, lipopolysaccharide; TLR4, Toll-like receptor 4;

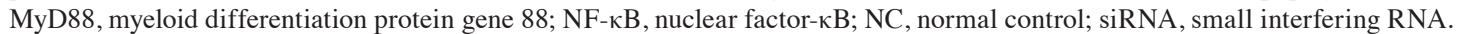

The current study measured Tim-3 expression in FLS from patients with RA using western blot analysis and RT-PCR. Consistent with previous studies $(18,19)$, the results of the present study demonstrated that Tim-3 expression in FLS from patients with RA was significantly higher than that of controls. Specific siRNA was designed to decrease Tim-3 expression. Although siRNA successfully decreased Tim-3 expression, Tim-3 expression increased following LPS stimulation even in cells transfected with Tim-3 siRNA. The results of the current study were consistent with those from Yang et al (20), indicating that LPS increased Tim-3 expression in macrophages in septic mice.

Tim-3 is a type of transmembrane protein belonging to the Tim family. Variable and mucin domains are included in the extracellular region of Tim-3, which may be expressed in active Th1 cells but not in Th2 cells (19). Tim-3 is also expressed on the surface of innate immune cells, including $\mathrm{CD}^{4+} \mathrm{T}$ cells, $\mathrm{CD}^{8+} \mathrm{T}$ cells, monocytes, $\mathrm{B}$ cells and natural killer cells (19). Typically, abnormalities of Tim-3 signaling pathway are associated with allergic, autoimmune and viral infectious diseases, including asthma, systemic lupus erythematosus, RA and aplastic anemia $(16,17)$. Tim- 3 potentially modulates the immune response by negatively regulating Th1 to inhibit the inflammatory reaction. It has been demonstrated that Tim-3 is highly expressed in $\mathrm{CD}^{4+} \mathrm{T}$ cells from patients with RA and positively associated with rheumatoid factors (19). In addition, Lee et al (18) demonstrated that levels of Tim-3 mRNA in the synovial tissue from patients with RA were higher than in healthy controls. Taken together, these results demonstrate that Tim-3 was expressed in the Th1 and synovial cells of patients with RA. In addition, Tim-3 overexpression may promote the activation and proliferation of tumor cells and macrophages (25-27). The present study also conducted a MTT assay to detect the effects of Tim-3 siRNA on the LPS-induced proliferation of FLS. The results demonstrated that LPS increased the viability of FLS in patients with RA. By contrast, Tim-3 silencing decreased cell viability in LPS-induced and control cells. 


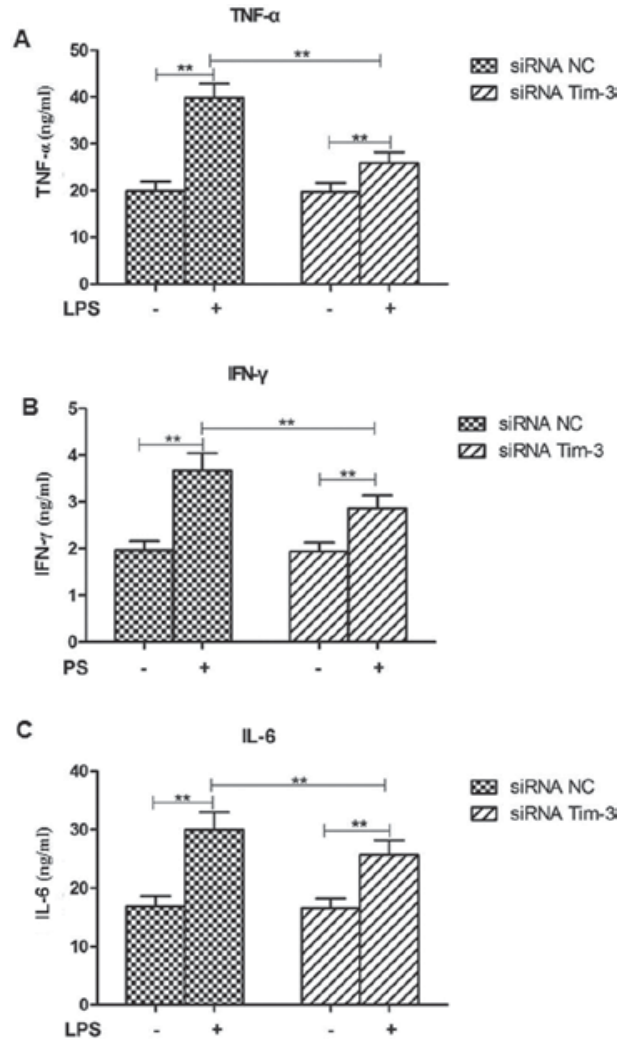

Figure 6. Tim-3 silencing decreases LPS-induced increases in (A) TNF- $\alpha$, (B) IFN- $\gamma$ and (C) IL-6 levels in the serum. ${ }^{* *} \mathrm{P}<0.01$. Data are presented as the mean \pm standard deviation. Tim-3, T-cell immunoglobulin mucin domain molecule-3; LPS, lipopolysaccharide; TNF- $\alpha$, tumor necrosis factor- $\alpha$; IFN- $\gamma$, interferon- $\gamma$, IL-6, interleukin-6; NC, normal control; siRNA, small interfering RNA.

The current study also measured the expression of TLR4, MyD88 and NF- $\mathrm{kB}$ p65 in different groups. The results of the present study suggest that LPS stimulated TLR4, MyD88 and NF- $\mathrm{KB}$ p65 expression. TLRs belong to the type I transmembrane protein family and 13 types have been identified so far (28). Among these subtypes, 10 exhibit functional activity, which may influence different types of pathogen associated molecular patterns (PAMPs) that mediate various biological effects (29). This is important as the majority of biological activities are closely associated with different immune-related diseases. TLR4 was the earliest TLR to be identified and is able to combine with PAMPs including LPS, mannose, tuberculosis and mycobacterium tuberculosis, as well as endogenous ligands (30). LPS is a common type of ligand (31). In the current study, it was determined that LPS is able to activate TLR4 and recruit MyD88 to activate the NF- $\mathrm{KB}$ signaling pathway. These data were consistent with those from previous studies, which demonstrated that TLR4 and NF- $\kappa$ B were activated in RA $(11,32)$. Therefore, TLR4 may be developed as a therapeutic target for RA. In addition to the inflammation-related signaling pathway, the current study measured cytokine levels. Consistent with the TLR4 signaling pathway, LPS stimulated TNF- $\alpha$, IFN- $\gamma$ and IL-6 expression, which were significantly attenuated by Tim-3 silencing.

In conclusion, the present study compared the expression of Tim-3 in normal FLS with RA FLS. The expression of Tim-3 in the FLS from patients with RA was increased. Tim-3 silencing decreased FLS viability and attenuated the LPS-induced inflammatory reaction. These data indicate that Tim-3 may be a therapeutic target for RA.

\section{References}

1. Robinson DE, Dennison EM, Cooper C, van Staa TP and Dixon WG: A review of the methods used to define glucocorticoid exposure and risk attribution when investigating the risk of fracture in a rheumatoid arthritis population. Bone 90: 107-115, 2016.

2. Calabrò A, Caterino AL, Elefante E, Valentini V, Vitale A, Talarico R, Cantarini L and Frediani B: One year in review 2016: Novelties in the treatment of rheumatoid arthritis. Clin Exp Rheumatol 34: 357-372, 2016.

3. GBD 2015 Mortality and Causes of Death, Collaborators: Global, regional, and national life expectancy, all-cause mortality, and cause-specific mortality for 249 causes of death, 1980-2015: A systematic analysis for the global burden of disease study 2015. Lancet 388: 1459-1544, 2016.

4. Kosmaczewska A, Swierkot J, Ciszak L and Wiland P: The role of Th1, Th17, and Treg cells in the pathogenesis of rheumatoid arthritis including anti-inflammatory action of Th1 cytokines. Postepy Hig Med Dosw (Online) 65: 397-403, 2011 (In Polish).

5. Talotta R, Berzi A, Atzeni F, Batticciotto A, Clerici M, Sarzi-Puttini P and Trabattoni D: Paradoxical expansion of Th1 and Th17 lymphocytes in rheumatoid arthritis following infliximab treatment: A possible explanation for a lack of clinical response. J Clin Immunol 35: 550-557, 2015.

6. Xia T, Zheng XF, Qian BH, Fang H, Wang JJ, Zhang LL, Pang YF, Zhang J, Wei XQ, Xia ZF and Zhao DB: Plasma interleukin-37 is elevated in patients with rheumatoid arthritis: Its correlation with disease Activity and Th1/Th2/Th17-related cytokines. Dis Markers 2015: 795043, 2015.

7. Friday SC and Fox DA: Phospholipase D enzymes facilitate IL-17- and TNFo-induced expression of proinflammatory genes in rheumatoid arthritis synovial fibroblasts (RASF). Immunol Lett 174: 9-18, 2016.

8. Swanson-Mungerson M, Incrocci R, Subramaniam V, Williams P, Hall ML and Mayer AMS: Effects of cyanobacteria Oscillatoria sp. lipopolysaccharide on B cell activation and Toll-like receptor 4 signaling. Toxicol Lett 275: 101-107, 2017.

9. Mukherjee S, Karmakar S and Babu SP: TLR2 and TLR4 mediated host immune responses in major infectious diseases: A review. Braz J Infect Dis 20: 193-204, 2016.

10. Liu Y, Yin H, Zhao M and Lu Q: TLR2 and TLR4 in autoimmune diseases: A comprehensive review. Clin Rev Allergy Immunol 47: 136-147, 2014.

11. Cerezo LA, Remáková M, Tomčik M, Gay S, Neidhart M, Lukanidin E, Pavelka K, Grigorian M, Vencovský J and Šenolt L: The metastasis-associated protein S100A4 promotes the inflammatory response of mononuclear cells via the TLR4 signalling pathway in rheumatoid arthritis. Rheumatology (Oxford) 53: 1520-1526, 2014.

12. Park SY, Lee SW, Baek SH, Lee CW, Lee WS, Rhim BY, Hong KW and Kim CD: Suppression of PU.1-linked TLR4 expression by cilostazol with decrease of cytokine production in macrophages from patients with rheumatoid arthritis. Br J Pharmacol 168: 1401-1411, 2013.

13. Arabski M, Fudala R, Koza A, Wasik S, Futoma-Koloch B, Bugla-Ploskonska G and Kaca W: The presence of anti-LPS antibodies and human serum activity against Proteus mirabilis S/R forms in correlation with TLR4 (Thr399Ile) gene polymorphism in rheumatoid arthritis. Clin Biochem 45: 1374-1382, 2012.

14. Schwärzler C, Oliferenko S and Günthert U: Variant isoforms of CD44 are required in early thymocyte development. Eur J Immunol 31: 2997-3005, 2001.

15. Nakae S, Iikura M, Suto H, Akiba H, Umetsu DT, Dekruyff RH, Saito H and Galli SJ: TIM-1 and TIM-3 enhancement of Th2 cytokine production by mast cells. Blood 110: 2565-2568, 2007.

16. Zhang XM and Shan NN: The role of T cell immunoglobulin and mucin domain-3 in immune thrombocytopenia. Scand $\mathrm{J}$ Immunol 79: 231-236, 2014.

17. Li Z, Ju Z and Frieri M: The T-cell immunoglobulin and mucin domain (Tim) gene family in asthma, allergy, and autoimmunity. Allergy Asthma Proc 34: e21-e26, 2013. 
18. Lee J, Oh JM, Hwang JW, Ahn JK, Bae EK, Won J, Koh EM and Cha HS: Expression of human TIM-3 and its correlation with disease activity in rheumatoid arthritis. Scand J Rheumatol 40: 334-340, 2011

19. Liu Y, Shu Q, Gao L, Hou N, Zhao D, Liu X, Zhang X, Xu L, Yue $\mathrm{X}$, Zhu F, et al: Increased Tim-3 expression on peripheral lymphocytes from patients with rheumatoid arthritis negatively correlates with disease activity. Clin Immunol 137: 288-295, 2010.

20. Yang X, Jiang X, Chen G, Xiao Y, Geng S, Kang C, Zhou T, Li Y, Guo X, Xiao H, et al: T cell Ig mucin-3 promotes homeostasis of sepsis by negatively regulating the TLR response. J Immunol 190: 2068-2079, 2013.

21. Wu FH, Yuan Y, Li D, Lei Z, Song CW, Liu YY, Li B, Huang B, Feng ZH and Zhang GM: Endothelial cell-expressed Tim-3 facilitates metastasis of melanoma cells by activating the NF-kappaB pathway. Oncol Rep 24: 693-699, 2010.

22. Chen ZZ, Zhang XD, Chen Y and Wu YB: The role of circulating miR-146a in patients with rheumatoid arthritis treated by Tripterygium wilfordii Hook F. Medicine (Baltimore) 96: e6775, 2017.

23. Zhu G, Wang X, Wu S and Li Q: Involvement of activation of $\mathrm{PI} 3 \mathrm{~K} / \mathrm{Akt}$ pathway in the protective effects of puerarin against $\mathrm{MPP}^{+}$-induced human neuroblastoma SH-SY5Y cell death Neurochem Int 60: 400-408, 2012.

24. Bottini N and Firestein GS: Duality of fibroblast-like synoviocytes in RA: Passive responders and imprinted aggressors. Nat Rev Rheumatol 9: 24-33,2013.

25. Cheng L and Ruan Z: Tim-3 and Tim- 4 as the potential targets for antitumor therapy. Hum Vaccin Immunother 11: 2458-2462, 2015.
26. Anderson AC: Tim-3, a negative regulator of anti-tumor immunity. Curr Opin Immunol 24: 213-216, 2012.

27. Ramello MC, Tosello Boari J, Canale FP, Mena HA, Negrotto S, Gastman B, Gruppi A, Acosta Rodríguez EV and Montes CL: Tumor-induced senescent $\mathrm{T}$ cells promote the secretion of pro-inflammatory cytokines and angiogenic factors by human monocytes/macrophages through a mechanism that involves Tim-3 and CD40L. Cell Death Dis 5: e1507, 2014.

28. Torices S, Alvarez-Rodríguez L, Varela I, Muñoz P, Balsa A, López-Hoyos M, Martinez-Taboada V and Fernández-Luna JL: Evaluation of Toll-like-receptor gene family variants as prognostic biomarkers in rheumatoid arthritis. Immunol Lett 187: 35-40, 2017.

29. Joosten LA, Abdollahi-Roodsaz S, Dinarello CA, O'Neill L and Netea MG: Toll-like receptors and chronic inflammation in rheumatic diseases: New developments. Nat Rev Rheumatol 12: 344-357, 2016.

30. Sestito SE, Facchini FA, Morbioli I, Billod JM, Martin-Santamaria S, Casnati A, Sansone F and Peri F: Amphiphilic guanidinocalixarenes inhibit lipopolysaccharide (LPS)- and lectin-stimulated toll-like receptor 4 (TLR4) signaling. J Med Chem: May 15, 2017 (Epub ahead of print).

31. Molteni M, Gemma S and Rossetti C: The role of toll-like receptor 4 in infectious and noninfectious inflammation. Mediators Inflamm 2016: 6978936, 2016.

32. He ZW, Qin YH, Wang ZW, Chen Y, Shen Q and Dai SM: HMGB1 acts in synergy with lipopolysaccharide in activating rheumatoid synovial fibroblasts via p38 MAPK and NF- $\kappa \mathrm{B}$ signaling pathways. Mediators Inflamm 2013: 596716, 2013. 